\title{
Role of ultrasonography in third trimester pregnancy for early diagnosis of embryonic demise
}

\author{
Asha Susawat $^{1}$, Rizwana Shaheen ${ }^{1}$, Komal Inani $^{1}$, Vikas Meena $^{2}$ \\ ${ }^{1}$ Department of Obstetrics and Gynaecology, Dr. S. N. Medical College, Jodhpur, Rajasthan, India \\ ${ }^{2}$ Department of ENT, S.M.S. Medical College, Jaipur, Rajasthan, India
}

Received: 25 March 2016

Accepted: 23 April 2016

\author{
*Correspondence: \\ Dr. Asha Susawat, \\ E-mail: asha.susawat@gmail.com
}

Copyright: () the author(s), publisher and licensee Medip Academy. This is an open-access article distributed under the terms of the Creative Commons Attribution Non-Commercial License, which permits unrestricted non-commercial use, distribution, and reproduction in any medium, provided the original work is properly cited.

\begin{abstract}
Background: The objective of antenatal care is to assure that every wanted pregnancy culminates in the delivery of healthy baby without impairing the health of the mother. The first trimester of intrauterine life is the most crucial period which needs careful eyes on the growing fetus inside. The aim and objective of this study was visualization \& localization of the gestational sac and early identification of embryonic demise and other forms of nonviable gestation.

Methods: A prospective study of 500 randomly selected patients with first trimester pregnancy at Dr. S. N. Medical College and attached group of hospitals, Jodhpur during May 2013 - November 2014. Ultrasound examination of these patients was performed to screen for fetal abnormalities \& uterine anomalies and identify those embryos that are still alive but at increased risk for embryonic and fetal demise.

Results: Out of 500 cases studied, 196 (39.2\%) pregnancies were normal. 304 cases had abnormal Ultrasonography findings. Out of these 304 cases, 87 had missed abortion, 70 had incomplete abortion and 53 cases had threatened abortion.

Conclusions: Ultrasonography has an important role in screening of early pregnancies for early diagnosis of fetal demise, fetal abnormalities and uterine anomalies With recent advances in technology, first trimester sonography can now detect, or at least suggest, many structural abnormalities.
\end{abstract}

Keywords: First trimester, Pregnancy, USG

\section{INTRODUCTION}

Although pregnancy may be classified as a normal physiological condition, it is associated with considerable risk to both mother and the offspring. The objective of antenatal care is to assure that every wanted pregnancy culminates in the delivery of healthy baby without impairing the health of the mother. Ultrasound has emerged as the gold standard imaging modality for patients presenting to the emergency department in the first trimester with pregnancy-related complaints.

The main goal of early detection is by no means termination of pregnancy. Studies have shown that prenatal detection of anomalies has not had an impact on the rate of termination. ${ }^{2}$ In fact, the value of early detection is multifold. If termination of pregnancy is an option, then the earlier it is accomplished, the less the maternal risks. ${ }^{3}$

In today's era where small family norm is the trend and where each \& every child's prenatal care is the great importance. The social phenomena of increasing maternal age predisposing to abortion, general limitation of family size and heightened expectation of normal outcome have produced increased pressure on the obstetrician, thereby giving more importance to ultrasonography. Ultrasound plays a role of utmost importance in confirming the 
pregnancy, site of pregnancy, viability and also in predicting whether a pregnancy has a good chance of continuing or it is destined to fail or has already failed.

\section{METHODS}

It is a prospective study of 500 randomly selected patients with first trimester pregnancy conducted at Dr. S. N. Medical College and attached group of hospitals, Jodhpur between May 2013 - November 2014. The study got ethical clearance from the institution and informed consent was taken from all the patients.

\section{Inclusion criteria}

Patients presenting with early pregnancy up to first trimester.

\section{Exclusion criteria}

- Second trimester pregnancy ultrasound.

- Third trimester pregnancy ultrasound.

Women of reproductive age with a missed period but a negative urine pregnancy test.

Clinical details like age, parity, obstetric history, personal history, medical history, past history, menstrual history and details of present pregnancy in terms of period of amenorrhoea at the time of episode of bleeding and pain abdomen or come for routine examination, amount and duration of bleeding whether associated with pain abdomen or not and history of expulsion of fleshy mass/clots were noted. A detailed clinical examination including complete general physical examination and pelvic examination was done to arrive at a provisional clinical diagnosis. Patients were then subjected to ultrasound examination. All patients were subjected to transabdominal sonography and transvaginal sonography was preferred whenever transabdominal sonography was inconclusive or equivocal.

- Data was collected in a preformed proforma

- Ultrasonographic evaluation of patients was done using the following machine.

ALOKA model no. - prosound $\alpha 6$ with convex multi frequency probe $(225 \mathrm{MHz})$.

Transabdominal sonography was done with 2-6 $\mathrm{mhz}$ frequency transducer and transvaginal sonography using 5-7 mhz transducer. Abdominal scanning was performed with a full maternal bladder, provides a wider field of view, and provides the greatest depth of view. Vaginal scanning was best performed with the bladder empty, gives a much greater resolution with greater crispness of fine detail.

Following parameters were studied:

- Visualisation and localisation of the gestational sac (intrauterine or ectopic pregnancy).
- Identification of embryonic demise and other forms of nonviable gestation.

- Diagnosis of fetal abnormalities and uterine anomaly.

- Identify those embryos that are still alive but at increased risk for embryonic and fetal demise.

- Multifetal pregnancies, number of embryo and the chorionicity- amnionicity.

- Duration or menstrual/gestational age of the pregnancy.

\section{RESULTS}

Table 1: Distribution of cases according to USG finding.

\begin{tabular}{|lll|}
\hline USG finding & No of cases & $\%$ \\
\hline Threatened abortion & 53 & 10.6 \\
\hline Incomplete abortion & 70 & 14 \\
\hline Complete abortion & 12 & 2.4 \\
\hline Missed abortion & 87 & 17.4 \\
\hline Blighted ovum & 36 & 7.2 \\
\hline Ectopic pregnancy & 29 & 5.8 \\
\hline Vesicular mole & 11 & 2.2 \\
\hline Inevitable abortion & 6 & 1.2 \\
\hline Normal early pregnancy & 196 & 39.2 \\
\hline Total & 500 & 100 \\
\hline
\end{tabular}

In present study out of 500 cases 286 cases (57.2\%) were multigravida and $214(42.8 \%)$ were primigravida. On Ultrasonography maximum $56.6 \%$ cases were of $6-8$ weeks gestational age, $22.8 \%$ of $8.1-10$ weeks gestational age and $16.8 \%$ cases were of 10.1-12 weeks gestational age. In $3.8 \%$ cases uterus size could not be made out but in these cases serum $\beta$-Hcg were positive.

Table 2: Cause of bleeding per vaginum in first trimester pregnancy (as per USG finding).

\begin{tabular}{|lll|}
\hline Causes & Number & $\%$ \\
\hline Abortions & 261 & 61.85 \\
\hline Ectopic pregnancy & 22 & 5.2 \\
\hline Vesicular mole & 11 & 2.60 \\
\hline Normal early pregnancy & 128 & 30.33 \\
\hline Total & 422 & 100 \\
\hline
\end{tabular}

On performing Ultrasonography of these cases we found that $196(39.2 \%)$ cases were early normal pregnancies. Cases of missed abortion, incomplete abortion, threatened abortion, complete abortion and blighted ovum were $17.4 \%, 14 \%, 10.6 \%, 2.4 \%$ and $14 \%$ respectively. There were 39 cases of ectopic pregnancy and 11 cases of vesicular mol. (Table 1).

$422(84.4 \%)$ of the cases presented with complaints of bleeding per vaginum and remaining 78 cases (15.6\%) presented without complain of any bleeding per vaginum. Out of these 422 cases presenting with bleeding per 
vaginum $261(61.85 \%)$ were abortions, $22(5.2 \%)$ were ectopic pregnancy and $11(2.6 \%)$ were vesicular moles. 128 normal early pregnancies also presented with bleeding per vaginum (Table 2).

Table 3: Various causes of abortion.

\begin{tabular}{|lll|}
\hline Abortions & No of cases & $\%$ \\
\hline Threatened abortion & 53 & 20.3 \\
\hline Incomplete abortion & 70 & 26.5 \\
\hline Complete abortion & 12 & 4.6 \\
\hline Missed abortion & 87 & 33.2 \\
\hline Blighted ovum & 36 & 13.7 \\
\hline Inevitable abortion & 6 & 2.3 \\
\hline Total & 264 & 100 \\
\hline
\end{tabular}

196 cases out of 500 cases presented with complaints of lower abdominal pain. Maximum incidence of abdominal pain was found in inevitable abortion $(83.33 \%)$ followed by incomplete abortion (61.4\%), complete abortion $(50 \%)$ and threatened abortion (43.4\%) (Table 4).

Table 4: Distribution of abortions with complaint of pain abdomen according to their usg findings.

\begin{tabular}{|llll|}
\hline $\begin{array}{l}\text { Abortions } \\
\text { (USG finding) }\end{array}$ & $\begin{array}{l}\text { No of } \\
\text { cases }\end{array}$ & $\begin{array}{l}\text { Pain } \\
\text { abdomen }\end{array}$ & $\%$ \\
\hline $\begin{array}{l}\text { Complete } \\
\text { abortion }\end{array}$ & 12 & 6 & 50 \\
\hline $\begin{array}{l}\text { Incomplete } \\
\text { abortion }\end{array}$ & 70 & 43 & 61.4 \\
\hline $\begin{array}{l}\text { Threatened } \\
\text { abortion }\end{array}$ & 53 & 23 & 43.4 \\
\hline Missed abortion & 87 & 7 & 12.43 \\
\hline $\begin{array}{l}\text { Inevitable } \\
\text { abortion }\end{array}$ & 6 & 5 & 83.33 \\
\hline Blighted ovum & 36 & 4 & 11.11 \\
\hline Total & 264 & 196 & 74.24 \\
\hline
\end{tabular}

Table 5: Distribution of cases according to treatment modalities.

\begin{tabular}{|lll|}
\hline Treatment & No of cases & $\%$ \\
\hline Conservative & 244 & 48.8 \\
\hline Laparotomy & 29 & 5.8 \\
\hline Dilatation and Evacuation & 204 & 40.8 \\
\hline Suction and Evacuation & 11 & 2.2 \\
\hline $\begin{array}{l}\text { No treatment (Complete } \\
\text { abortion) }\end{array}$ & 12 & 2.4 \\
\hline
\end{tabular}

\section{DISCUSSION}

USG is a boon to obstetric practice and it has been used by obstetrician very frequently. The USG examination should be a must at least once in each trimester. This will confirm the viability, the position of fetus and any pathology present.
A normal pregnancy with excellent chances for a viable birth could be differentiated using ultrasound from a pathological pregnancy which warrants an immediate termination. In daily obstetric practice bleeding in early pregnancy is common event that herald an abnormality interrupting the normal development of an early gestation. Clinical problem varies widely from one in which it is hardly life threatening where diagnosis and therapy are straight forward to one which may endanger the life of the mother. Nearly $25 \%$ of all pregnant women in their first trimester complain of bleeding. By mere clinical history and examination definitive diagnosis is usually impossible. The causes of bleeding are many and cover a spectrum of conditions ranging from a viable pregnancy to non-viable pregnancy. Ultrasonography has opened new dimensions in early pregnancy complications so that specific treatment medical or surgical can be immediately instituted.

Ultrasound examination gives a good index for evacuation in cases of abortion other than threatened abortion. The sonographic landmarks of first trimester of pregnancy have been well recognized and include identification of gestational sac, fetal pole, fetal cardiac activity, yolk sac and amnion. The invaluable role of these landmarks, gestational sac and fetal biometry in diagnosing pathological pregnancy and predicting pregnancy outcome has been clearly documented. The first twelve week of intra uterine life are the most crucial period which needs a careful eye on the growing fetus inside.

The three major cause of first trimester complication are abortion, ectopic pregnancy and molar pregnancy. Ultrasound helps in assessing the type of abortion. Early diagnosis and better management including post evacuation follow up of molar and preventing its malignant sequelae can be achieved by sonography. Ultrasound and serum $\beta$ HCG titres are complimentary in the follow up.

Total number of 500 randomly selected cases included in present study. In present study $56.6 \%$ of patients had bleeding at 6-8 weeks of gestation which is comparable to Bharadwaj $\mathrm{N}$ study of $30 \% .^{4} 22.8 \%$ of cases had bleeding in between 8.1-10 weeks compared to $35 \%$ of Bharadwaj N study and $16.8 \%$ had bleeding between $10-$ 12 weeks compared to $22 \%$ of Bharadwaj $\mathrm{N}$ study.

Out of 500 cases $422(84.4 \%)$ presented with complaint of bleeding per vaginum which is the most common complaints of complication of first trimester of pregnancy (Table 2). 196 (39.2\%) cases presented with complaints of lower abdominal pain (Table 4).

Out of 500 total cases 53 patient diagnosed by USG as threatened abortion and out of them 50 cases taken on conservative management and in 3 cases Dilatation \& Evacuation done. 87 cases diagnosed missed abortion by USG and most of these cases presented to hospital for 
routine check-ups or dirty discharge. Uterine size did not correspond to the period of amenorrhoea in these cases. Out of 500 cases 36 cases diagnosed as blighted ovum in which patient usually have no complaints or presented with pain abdomen, blighted ovum which is diagnosed only by ultrasound. All these patients were treated by Dilatation and Evacuation. 11 (2.2\%) cases diagnosed as a vesicular mole and all were treated with Suction and Evacuation. 12 cases diagnosed by USG as complete abortion and no surgical treatment required in them. (Table 1)

29 cases out of 500 present with ectopic pregnancy which is an obstetric emergency, and needed urgent evaluation and treatment to save the patient. Out of 500, 196 cases came to hospital for routine check-ups and complaint of spotting and pain abdomen. USG done and they were treated conservatively. No case was diagnosed as complete abortion on clinical examination but 12 were sonologically diagnosed (Table 1).

In present study various abortions contributed to a major cause of first trimester bleeding constituting $61.85 \%$ (Table 2). In ReddiRani P, Bhargava SK study group also abortion is the leading cause of early pregnancy bleeding with an incidence of $61 \%$ and $81.6 \%$ respectively. 5,6

Table 6: Distribution of cases based on USG diagnosis comparison with some studies available.

\begin{tabular}{|llll|}
\hline $\begin{array}{l}\text { Causes of } \\
\text { bleeding }\end{array}$ & Sofat $\mathbf{R}^{11}$ & $\begin{array}{l}\text { Bhardwaj } \\
\mathbf{N}^{4}\end{array}$ & $\begin{array}{l}\text { Present } \\
\text { study }\end{array}$ \\
\cline { 2 - 4 } & $\%$ & $\mathbf{\%}$ & $\mathbf{\%}$ \\
\hline $\begin{array}{l}\text { Threatened } \\
\text { abortion }\end{array}$ & 50 & 57 & 28.7 \\
\hline $\begin{array}{l}\text { Missed } \\
\text { abortion }\end{array}$ & 10 & 8 & 11.8 \\
\hline $\begin{array}{l}\text { Blighted } \\
\text { ovum }\end{array}$ & 12 & - & 23.1 \\
\hline $\begin{array}{l}\text { Incomplete } \\
\text { abortion }\end{array}$ & 2.2 & 26 & 3.9 \\
\hline $\begin{array}{l}\text { Complete } \\
\text { abortion }\end{array}$ & - & - & 2 \\
\hline $\begin{array}{l}\text { Inevitable } \\
\text { abortion }\end{array}$ & 3.3 & - & 9.5 \\
\hline $\begin{array}{l}\text { Ectopic } \\
\text { pregnancy }\end{array}$ & 9 & - & 3.6 \\
\hline $\begin{array}{l}\text { Vesicular } \\
\text { mole }\end{array}$ & 5.5 & 4 & \\
\hline
\end{tabular}

The incidence of ectopic pregnancy is $5.8 \%$ (Table 1) which is almost near to Bhargava SK study. ${ }^{6}$ The incidence of mole in present study is $2.2 \%$ (Table 13) compared to other studies of ReddiRani $\mathrm{P}$ et al and Bhargava SK who had an incidence of $18 \%$ and $4.35 \%$ respectively. ${ }^{5,6}$
In our study the incidence of viable pregnancies on ultrasound is $51 \%$ and $49 \%$ of non-viable pregnancies which is similar to Hertz et al study. ${ }^{7}$ Schauberger CW et al, Nyberg et al and Stabile et al had an incidence of $28 \%$, $44 \%$ and $64 \%$ of viable pregnancies and $72 \%, 52 \%, 36 \%$ of non-viable pregnancies respectively. ${ }^{8-10}$

In present study among various cause of bleeding per vaginum in first trimester 261 cases $(61.85 \%)$ were of various abortions and $22(5.2 \%)$ were of ectopic pregnancy and $11(2.6 \%)$ had vesicular mole (Table 2 ).

Missed abortion (33.2\%) in first trimester pregnancy was the commonest type in the present study (Table 3).

Out of 500 cases 196 patient present with complaint of pain abdomen either dull in nature or cramping nature. In which there were 6 out of cases of complete abortion, 43 out of 70 cases of incomplete abortion, 23 out of 53 cases of threatened abortion, 7 out of 87 cases of missed abortion, 5 cases out of 6 cases of inevitable abortion and 4 out of 36 cases of blighted ovum. Inevitable abortion presented with $83.33 \%$ pain abdomen (Table 4 ).

Most of the patients $(48.8 \%)$ were managed conservatively. $204(40.8 \%)$ cases were treated by Dilatation and Evacuation, laparotomy done in 29 (5.8\%) cases and in 11 cases Suction \& Evacuation done (Table 5 ). The majority of cases were of missed abortion, followed by incomplete abortion. The result of present study co-relate well with Sofat $\mathrm{R}$ et al and Bhardwaj $\mathrm{N}$ et al (Table 6). ${ }^{4,11}$

\section{CONCLUSION}

Ultrasound is today an integral part of the obstetrician's armamentarium - almost an extension of the examining finger. The available evidence does not indicate any deleterious biologic effects on the mother or the fetus from the use of diagnostic ultrasound, and the benefits outweigh the risk if any.

Women undergoing ultrasound examination must be treated with respect and care. They must be reassured about the "painlessness" and safety of the examination, particularly in the context of the fetus. A brief overview of the information required by the clinician should be conveyed. Appropriate clinical information and consent forms should be completed as per institutional and legal requirement. Patient privacy and confidentiality should be maintained. Prior to changing, the patient should be reminded not to pass urine as a full bladder is required for first trimester ultrasound scans. Fasting is usually not required unless the upper abdomen is to be scanned as well.

The goals of first trimester sonography include visualization and localization of the gestational sac (intrauterine or ectopic pregnancy) and early identification of embryonic demise and other forms of 
nonviable gestation. Women with bleeding $\mathrm{p} / \mathrm{v}$ in early pregnancy coming to obstetrician are anxious about the outcome of pregnancy, reassuring USG and hormonal findings give psychological support regarding the outcome.

The advantage of early pregnancy check-up can be spread via media to general population. It will be worth using the media. Combination of awareness among general population and various schemes by government will definitely improve women and child health care.

Till now it was thought that nothing was better than the two fingers of an obstetrician, but today Ultrasound has a definite edge over it in the first trimester.

Funding: No funding sources

Conflict of interest: None declared

Ethical approval: The study was approved by the Institutional Ethics Committee

\section{REFERENCES}

1. American College of Emergency Physicians. Emergency Ultrasound Imaging Criteria Compendium. Annals of Emergency Medicine. 2006; $48: 487-510$.

2. Offerdal K, Blaas HGK, Eik-Nes SH. Impact of 15 years of prenatal ultrasound examination on trends in termination of pregnancy in a non-selected population of 41,382 births in Norway [abstract]. Ultrasound Obstet Gynecol. 2007;30(suppl):369-70.
3. Barlett LA, Berg CJ, Shulman HB, et al. Risk factors for legal induced abortion-related mortality in the United States. Obstet Gynecol. 2004;103:729-37.

4. Bharadwaj N. Sonography evaluation as an aid in the management of bleeding in early pregnancy. Journal of obstetrics and Gynaecology of India.1988;38:6402.

5. Reddirani P, Sunita V. Ultrasound Evaluation of cause of vaginal bleeding in first trimester of pregnancy. J Obstet Gynecol Ind. 2000;50(1):54-8.

6. Dimri R, Bhargava SK. Transvaginal sonography in obstetrics and Gynaecology, New Deilhi, India. 1988;44:97-159.

7. Hertz JB, Mantoni M, Svenstruck B, threatened abortion studied by estradiol 17 beta in serum and ultrasound. Obstet gynecol. 1980;55:324-8.

8. Schauberger CW, Mathiason MA. Ultrasound assessment of first trimester bleeding. Obstet gynecol 2005;105:333-8.

9. Nyberg DA, Laing FC, Filly RA. Ultrasonographic differentiation of the Gestational sac of early intrauterine pregnancy from pseudo-gestational sac of ectopic pregnancy. Radiology. 1983;146:755-9.

10. Stabile I, Campbell S, Grudzinskas JG. Ultrasonic assessment of complication during first trimester of pregnancy. Lancet. 1987;2:1237-40.

11. Sofat R. Ultrasound evaluation of bleeding in early pregnancy: Journal of obstetrics and Gynaecology of India.1987;31:344-7.

Cite this article as: Susawat A, Shaheen R, Inani K, Meena V. Role of ultrasonography in third trimester pregnancy for early diagnosis of embryonic demise. Int J Reprod Contracept Obstet Gynecol 2016;5:1865-9. 